\title{
SWOT Analysis of Developing Circular Economy in Small and Medium Enterprises in Hunan Province
}

\author{
Jingyi Wang ${ }^{1, a}$ \\ ${ }^{1}$ Hunan Biological and Electromechanical Polytechnic \\ Changsha, China \\ axiguawjy@163.com
}

\begin{abstract}
Keywords: SMEs, recycling economy, SWOT
Abstract. At the present stage, China has become more and more demanding in terms of resource utilization. The development mode of circular economy also came into being. Its purpose is to reduce pollution emissions, improve environmental and resource utilization, and fundamentally coordinate the relationship between economy and natural resources. As the main body of the development of circular economy, the development of SMEs is subject to many factors, such as backward technology, lack of concentration of enterprises, market failure and cost issues. This article analyzes the status quo and the restrictive factors of circular economy development of small and medium-sized enterprises in Hunan Province through the SWOT analysis method, and puts forward the corresponding principles and contents of the support system.
\end{abstract}

\section{Introduction}

Hunan is a relatively economically developed province in central China with abundant wetland resources and many developing small and medium-sized enterprises. To help local small and medium-sized enterprises to develop a recycling economy can both improve the local environment and help enterprises to achieve sustainable development.

\section{An overview of SWOT analysis methods}

SWOT analysis is a scientific analysis method that combines the internal resources and external environment of an enterprise by analyzing its own competitive advantages, disadvantages, opportunities and threats. At the overall level, SWOT can be divided into two parts: SW and OT, among which SW represents the analysis of strengths and weaknesses, and the investigation mainly focuses on the internal conditions. The latter represents the opportunities and threats (OT). The main consideration is external conditions.

\section{SWOT Analysis of Developing Circular Economy in Small and Medium Enterprises in Hunan Province}

\section{Internal resources.}

(1) Internal advantages. Hunan's SMEs mainly have two internal advantages when developing circular economy: technology cost advantage and product competitive advantage. At present, the new impetus for the development of SMEs in Hunan is technological transformation. With the increasing intensity of technological transformation, the province's SMEs began to gradually implement and promote some new technologies with high-tech content and strict environmental standards and guided by the concept of cleaner production. Moreover, there are many scientific research units in Hunan Province. The strength of science and technology has promoted the implementation of technological innovation of enterprises and renovated the production technology, which has provided rich human resources and advanced scientific research results for the promotion of circular economy. In addition, due to its unique geographical advantages, Hunan Province is known as a good district with abundant fish and rice. As a result, Hunan Province has a very good ecological environment. With the 
development and production of green food and green, the development of agriculture has obvious advantages. In recent years, SMEs in Hunan have given full play to these advantages. They have been striving for a "green card" and have taken a green production path with their own characteristics. The achievements in the development and expansion of the green food industry have been remarkable.

(2) Internal disadvantage. Analysis of its internal weaknesses, we can find that the development of circular economy in Hunan SMEs played a restrictive role in the development of the most important factor is the financing difficulties. Judging from the current situation, the absolute proportion of SMEs in Hunan Province in the total number of enterprises in the province plays a crucial role in ensuring people's livelihood and social stability. However, this part

Enterprises for the development of circular economy investment and financing methods and ways are relatively simple. In addition, because their capital markets are not perfect enough, many small and medium-sized enterprises are hampered in their investment and financing and are unable to obtain the capital necessary for technological innovation in cleaner production. Owing to the restriction of their own conditions, the financing channels for small and medium-sized enterprises in Hunan are very narrow, often confined to seeking venture capital, project financing and government subsidies. And this countless financing channels will be subject to policy restrictions, investment environment constraints, bank discrimination and other factors, making it more difficult for SMEs in the investment and financing. From the fund supply level, private lending and fund-raising are considered as unlawful acts, while the capital markets such as stocks and funds have not been opened yet. The number of small and medium-sized joint-stock banks that provide corporate loan services is small, which makes the long-term self-accumulation of SMEs in Hunan They have almost no channels for financing, thus losing a lot of opportunities for development, and indirectly hinders the innovation and development of enterprises.

\section{External environment}

(1) External opportunities. The government's attention and promulgated policies and regulations are the most important external opportunities for the development of circular economy in Hunan SMEs. With the popularization of circular economy concept across the country, all members of the community think that the development of circular economy is a necessary way to build an overall well-to-do society. It can change the mode of economic growth and is conducive to a resource-saving and environment-friendly society Construction. All parts of the country have attached great importance to the development of circular economy and supported it from all aspects. Hunan Province also quickly responded to the national policy and actively implemented a large number of advanced enterprises that made comprehensive use of resources. They are now making great strides toward the development of an advanced model of recycling economy. In order to promote the development of circular economy in SMEs, both the state and Hunan Province have formulated a series of policies and regulations to create a favorable policy environment for sound and rapid development of circular economy. Through the macro-control of the government, the market behavior of cleaner production should be standardized so that the market environment will be orderly, just and equitable, and eventually a circular economy transformed from a business cycle to a regional cycle and finally a national cycle will be formed.

(2) External threats. In the process of developing circular economy, the external threats to Hunan SMEs include the threat of asymmetric information, the threat of resource endowments and the threat of institutional innovation lag. Among them, the threat of institutional innovation lags behind is the most important factor.

For public goods, the allocation problem cannot be solved in a negotiated way. The negotiation is not only inefficient but also inefficient, but also difficult to operate. Environment and resources as a public product, this is no exception. Circular economy is an innovation in the economic activities of mankind. It is a new economic form that can avoid pollution as much as possible in the course of economic development, and at the same time, does not confer any rights on the environment to pollute the environment. Innovation system can guarantee the effective implementation of circular economy. Under the current circumstances, Hunan Province has paid too much attention to technology in the development of circular economy, neglecting the system, and the systems lack systematic and dynamic 
timeliness. Most of them are still in theoretical discussion or pilot stage, which hinders the development of micro-cleaner production activities.

\section{Strategic Choice of Developing Circular Economy for Small and Medium Enterprises in Hunan Province}

Through SWOT analysis shows that the developments of circular economy in SMEs in Hunan Province to take appropriate external opportunities dominated and actively explore the strategy. The internal and external environment of SMEs in Hunan Province shows that the development status of circular economy is basically achieved under the support of policy making or government preferential conditions. This means that policies and systems are the driving force for its development. After all the influencing factors In the policy and system support the most obvious role. In addition, for all SMEs, policies and systems also play an important role as the precursor to the development of enterprises. For example, Hunan provincial government fees and charges for the provisions of the regulations, the development of circular economy preferential policies for SMEs, resource-intensive enterprises on the high taxes, etc., have shown that the system and policy of SME recycling economy from the small and medium enterprises in Hunan Province SWOT analysis of the development of recycling economy is decisive, and SMEs are just the recipients and performers of these systems and policies. As a result, the Hunan provincial government's policy and circular economy are not only the local SME's development of circular economy, the implementation of the basis and premise of cleaner production, but also its necessary guarantee. The SWOT analysis also pointed out that the internal conditions of enterprises are also the support for the development of circular economy in SMEs, and their technology, capital and product competitiveness play an important role. Therefore, when implementing institutional innovation and policy support for SMEs, the government should also support such factors as technology, capital and products. For SMEs to develop their strategies, it is necessary to give full play to their own advantages and also accept the support of the government, the society and the market in order to gain more opportunities for development and expand the space for development.

\section{The Construction of Supporting System to Develop Circular Economy in Small and Medium Sized Enterprises in Hunan Province}

\section{The principle of construction.}

Under the premise of the development of socialist market economy, the establishment of all kinds of economic systems must follow the corresponding principles. The same is true for small and medium-sized enterprise circular economy system, based on three principles: First, the principle of supporting the system. That is, based on the principle of matching, the four systems of the conversion system, technological innovation system, capability enhancement system and the policy and institutional environment system needed for the development of SME-UBE financial capital should be established to form a multi-angle development support system. Second, the principle of functional complex refers to the full utilization and integration of similar functions in the process of building a recycling economy model for small and medium-sized enterprises. Third, the guiding principle of the government. Refers to through the economic cycle system, the government leadership into government guidance, the profit agencies and non-profit institutions to coordinate and improve, increase the existing funds and lead to the utilization of funds.

\section{Build content.}

(1) Institutional innovation support system. Small and medium-sized enterprises in Hunan Province, the development of circular economy system innovation support system needs to be built from two levels. First, the legal system innovation, circular economy legislation determines the promotion of circular economy in SMEs. By drawing on the legislative support system of Germany, Japan and the United States, efforts can be made in three aspects: the legal system of property rights, the market legal system and the legal system of enterprises. As for the legal system of property rights, Hunan should strengthen its system of legal system of intellectual property with local characteristics, systematize and 
legalize the local small and medium-sized agricultural and forestry technologies, and enable enterprises to produce technical patents more quickly and easily and transfer their achievements. Finally, promote the development of circular economy. In terms of market legal system, Hunan Province should incorporate the market regulations on protection and promotion of green consumption into the market legal system and encourage small and medium-sized enterprises to adopt green consumption policies in their local cleaner production policy documents. In terms of corporate legal system, in light of the development characteristics of small and medium-sized enterprises in Hunan Province, we should jointly act on the clean production and pollution prevention and control of SMEs through mandatory restraint and policy encouragement, and support small and medium-sized enterprises in agriculture and forestry to encourage them to develop eco-cyclical agriculture As well as forestry, to promote cleaner production among industries and industries.

Secondly, the policy system innovates, which mainly includes the incentive policy system and mandatory policy system. In terms of incentive policies and systems, the Hunan provincial government should encourage SMEs to construct and rehabilitate their prevention and control facilities with the necessary financial and tax measures, such as providing financial subsidies or concessional loans to enterprises for pollution prevention and control equipment and technology research Utilization, reduce resource consumption. Mandatory measures regulate and control the economic behavior of producers and consumers, so that recycling economy and people's interests linked, such as the provisions of the disclaimer to pay for the collection and re-commercialization of waste appliances and other related costs, forced by some charging measures. The public make effective use of resources.

(2) Technical innovation support system. Taking into account the actual situation in Hunan Province and the difficulties faced by local SMEs in developing circular economy, a technological innovation support system should be set up. The system should be led by the government so that all SMEs can actively participate in the system. Through joint universities and research institutes, from the perspective of the whole society, it will give support to the development of circular economy in small and medium-sized enterprises in Hunan Province. The support system should be based on the guarantee and support of SMEs technological innovation and should be constantly improved in terms of information, manpower, services and technologies so that the innovative operation mechanism can be nurtured and encouraged so as to make the sources of information more extensive and at the same time Innovation Achievements The booming and orderly trading market has finally led to an increase in regional innovation across Hunan Province, creating an innovative cluster of circular economy and improving the level of development of the local circular economy. On the manpower front, incentive mechanisms for talents, personnel use mechanisms and personnel training mechanisms should be established to devote more talents to the development of SMEs in order to solve such problems as lack of qualified personnel and backward production technology. Technology, research and development of cleaner production technology, pollution control technology, waste recycling technology and new energy technologies, technological innovation for SMEs to provide cleaner production support. Information, improve the network infrastructure, construction of small and medium-sized enterprise information and information resources, construction of technical databases, expert databases and policy information base in order to play a link of information resources and innovative resources agglomeration, technology innovation system to enable the elements Effective communication with the outside world.

\section{References}

[1] Maurice J . Caullery, Parasitism and Symbiosis [ M ] . London: Sidgewick and Jackson , 1952

[2] Pieter H. Pellenbarg, Sustainable Business Sites in the Netherlands: A Survey of Policies and Experiences [J]. Journal of Environmental Planning and Management, 2002. Vol.45 (1) 
[3] Extended Producer Responsibility:a Guidance Manual for Governments. OECD.

http://www.oecdbookshop.org/oecd/display.asp?sfl=identifiers\&lang=EN\&st1=972001041p1 . 2001 